\title{
Narrative Pedagogy for Introduction to Philosophy
}

\author{
KEVIN J. HARRELSON \\ Ball State University
}

\begin{abstract}
This essay offers a rationale for the employment of narrative pedagogies in introductory philosophy courses, as well as examples of narrative techniques, assignments, and course design that have been successfully employed in the investigation of philosophical topics. My hope is to undercut the sense that "telling stories in class" is just a playful diversion from the real material, and to encourage instructors to treat storytelling as a genuine philosophical activity that should be rigorously developed. I argue that introductory courses focused on student narratives fulfill the ideals of learning-centered teaching. Since narrative learning also promotes self-knowledge and empathic understanding, there is good reason to consider replacing or supplementing canonical texts or arguments with narrative assignments. The concluding sections provide details as to how such assignments can be constructed, integrated into course units, and assessed.
\end{abstract}

Narrative is nearly ubiquitous in the current academic culture. Psychologists and counselors have developed theories and practices of narrative therapy. ${ }^{1}$ Communications theorists have for decades considered narrative as paradigmatic for human communication. ${ }^{2}$ Education theorists have developed theories and methods of narrative pedagogy. ${ }^{3}$ Literary critics and historians, having trafficked in narrative for a considerably longer spell, have had an easy time inserting themselves into the mix. Cultural theorists have gone as far as to argue that reality as such is narratively constructed. ${ }^{4}$ In legal theory narrative has put the notion of a fact into question. ${ }^{5}$ These trends are significant enough that they have yielded interdisciplinary publications, specialty journals, and even curricular programs devoted exclusively to narrative studies. ${ }^{6}$ Never the first to adopt a fashion, it might seem that we philosophers do well to resist this fascination with storytelling. Our business is not with the particularity of stories, but with knowledge of universals. We are not interested in the details of events, but rather in the laws that regulate 
them. We demand arguments, and do not settle for anecdotes. Fiction and invention do not concern us as much as does truth. Mainstream academic philosophy thus quite understandably finds itself at odds with this narrative moment in academic culture.

I begin with this contrast in order both to prioritize the sharpest point of resistance to the proposals I make in this essay, and to give an account-I might say tell a story-of the reluctance of philosophers to adopt narrative models. Foregoing any attempt to define philosophy, I acknowledge that argument, universality (or at least generality), and some understanding of truth are central to it, and thus that the case of philosophy poses special challenges for the theorist of narrative and the narrative pedagogue. ${ }^{7}$ Nonetheless I think that philosophy can be introduced through narrative with great benefit both to students and to the profession. In this context "narrative pedagogy" refers to any approach to teaching and learning that replaces or supplements written, canonical texts with a combination of instructor and student narratives. Narrative pedagogues are instructors who teach by relating and soliciting stories, placing some degree of priority on this over other methods such as, in the case of philosophy, the analysis of texts or arguments. This essay offers a rationale for the employment of narrative pedagogies in introductory philosophy courses, as well as examples of narrative techniques, assignments, and course design that have been successfully employed in the investigation of philosophical topics. My hope is to undercut the sense that "telling stories in class" is just a playful diversion from the real material, and to encourage instructors to treat storytelling as a genuine philosophical activity that should be rigorously developed.

Since the appropriateness of narrative pedagogy for philosophy is open to question, I begin with a theoretical defense of its use in the discipline. The first section offers a preliminary rationale for the inclusion of narrative methods specifically in introductory philosophy courses. After illustrating some of the many ways in which narrative approaches have long pervaded philosophical traditions, I highlight some advantages of narrative over argument in developing traditional values such as self-knowledge and empathic understanding. I also reply to some skeptical objections to narrative philosophical pedagogy. In the second section I discuss a number of issues in regard to the content of narrative philosophy. I explain how narrative helps to integrate syllabi so that skill development and other learning objectives play a greater role in course planning, and I argue that the exceptional emphasis on relevance and flexibility in narrative curricula better fulfills the ideals of learning-oriented teaching. This discussion includes some sample assignments intended to serve as models for aspirant narrative pedagogues. In the last section I address some of the nuances of 
narrative course design, and provide more detailed examples of how narrative assignments can be structured in order to foster maximally significant learning experiences. All examples are drawn from my own forty-student introductory course at a large public university, a course populated mainly by students who enroll in order to fulfill a requirement for the core curriculum. ${ }^{8}$

Narrative pedagogy requires no general defense in this essay. There is an abundance of evidence of the effectiveness of narrative in inspiring belief change, providing the context for transformative experiences, and communicating information. ${ }^{9}$ To give just one very relevant example, people are more likely to reject a previously held belief or opinion as a result of narrative persuasion than they are by most other techniques, such as the abstract argument that philosophers hold so dearly. ${ }^{10} \mathrm{Ob}$ servations of this type, of course, will not persuade the more staid and resistant strains of our intellectual identity. In response we appeal to several of our most cherished narratives that divide the philosophers from the sophists, logic from rhetoric, etc. We philosophers have standards of good argument that cannot be overturned with empirical data about persuasion and belief modification, and we know that the best arguments are not always those with the most popular appeal. These precious argumentative standards are buffered by stories about people like Socrates who shunned rhetorical success (though we do not likewise follow Socrates in refusing remuneration for our teachings). Without reducing truth to persuasion, however, we can acknowledge that a sound argument with no rhetorical power is useless as a pedagogical tool, and it is the teaching of philosophy to large numbers of paying college students that is at issue here. The basic distinctions associated with the anti-rhetorical version of Socrates thus require some qualification.

In this section I specifically challenge the distinction between argument and narrative with a view to establishing a pedagogical purpose for narrative in philosophy. "Argument" is taken in the inferential sense of the term, rather than in the broader interpersonal sense. The former involve premises, conclusions, and identifiable norms of inference. The latter sense encompasses any rhetorical exchange between or among persons, and so is much less at odds with narrative. "Narrative" is taken in its common sense of recounted story, and I make no specific appeal to the formal characteristics of narrative (causal or chronological relations; endpoint or closure; emplotment; privileged perspective, etc.). ${ }^{11}$ I begin by suggesting that narrative has been integral to philosophy at many points in its history, so that narrative approaches are more 
traditional than they might seem. My intent here is to underline the provincial aspects of the exclusive emphasis on argument over narrative. I then argue that several efficient and common methods of constructing arguments involve recounting narratives, so that narrative and argument are less at odds than some might insist. Third, I address a selection of skeptical objections, and distinguish narrative pedagogy from other techniques such as teaching philosophy through film. Finally, I discuss the specific pair of learning objectives, self-knowledge and empathy, that are better met with narrative than with an argumentative approach.

A brief overview of common literary genres in the history of philosophy should remove considerable force from any suggestion that arguments in the inferential sense have always or even usually served as the basic elements in philosophical discussion. Plato deserves the beginning here as elsewhere: he wrote dialogues, a narrative genre, in which arguments occasionally appear deeply embedded in narrative contexts. ${ }^{12}$ Socrates indeed provides some inferential arguments for philosophical theories such as anamnesis or the immortality of the soul. But we should recall that these arguments are placed in the mouth of a fictional or quasi-fictional character. Further, even the initial voicing of the arguments is often recited by a second layer of narration (in some cases, as in the Parmenides, there is a third or a fourth). ${ }^{13}$ Beyond these literary techniques, we have also to consider the intermingling of argument with myth, allegory, and other narrative elements (the Cave, the Divided Line, the Myth of Er, the Chariot, the wonderful story about how Zeus divided two-headed, four-limbed humans in half, etc.). ${ }^{14}$ At any rate, it is far from obvious that we should consider arguments in the inferential sense, or their theoretical conclusions, as the basic unit in Platonic texts. A contemporary reader might overlook all else in hightailing to the premises and inference types of identifiable arguments, but the extent to which this should qualify as good philosophical reading is a matter for serious debate. ${ }^{15}$

Plato is just one author, and so what may or may not hold for him is of limited consequence for this discussion. How much narrative is there in philosophical literature after Plato? Hume, Berkeley, Malebranche, and Diderot also wrote philosophy in dialogue. ${ }^{16}$ Plutarch, Laertius, and many others wrote philosophy in biography; Schopenhauer recommended but did not practice that genre; and Augustine, Rousseau, Nietzsche, and Collingwood wrote philosophy in autobiography. Nietzsche went as far as to subsume all philosophy within the genre of autobiography, although it is perhaps excessive to usurp this observation for my case. ${ }^{17}$ Dante and T. S. Eliot wrote philosophy in poetic narratives, while Dostoevsky, Camus, and Sartre wrote it in short stories, novels, and plays. If Augustine and other catholic philosophers wrote philosophy as prayer, Boethius combined this form with the 
dialogue in his Consolation of Philosophy. Bonaventure wrote a kind of travel-log, though not one that described a physical journey. ${ }^{18}$ Descartes's most famous work has a thoroughly narrative form, although contemporary philosophers are apt to separate the arguments from the narrative. ${ }^{19}$ We abstract the argumentative syllogisms from the lived and recounted story of a human being questioning his beliefs, as if the narration were the mere dressing of the argumentative bird. If we take into account also histories of philosophy as a literary subgenre that comprises a good portion of the extant philosophical literature, then we move yet more of the relevant literature into the narrative camp. The sum of these references suggests that any insistence on the priority of the inferential argument over narrative has an abundance of historical evidence against it.

Not only has narrative played a prominent role in the literary genres that philosophy has assumed, but it has also received some recognition for its place in the architecture of reason itself. Several strains of recent philosophical research have attempted to modify our understanding of rationality in such a way as to lend narrative an increasingly central role. Rationality has lately taken, on some accounts at least, less of an inferential and more of a narrative form. A detailed history of this trend might start with an obscure strain of German neo-Kantianism, and Wilhelm Schapp's 1955 book translatable as Entangled in Stories. ${ }^{20}$ The seminal moment in anglophone philosophy, however, occurred several decades later when Alasdair MacIntyre argued in After Virtue that the human is primarily a storytelling creature, and he suggested that narrative is the key to personal identity, the analysis of behavior, and other standard topics. ${ }^{21}$ Soon thereafter Charles Taylor began to develop similar ideas. ${ }^{22}$ Paul Ricoeur took these points much further, devoting his later career to the theory of narrative and the role of this in the philosophy of history, the metaphysics of time, etc. ${ }^{23} \mathrm{~A}$ number of academic philosophers have continued this work, though mainly within terms set either by Ricoeur or by Taylor and MacIntyre. ${ }^{24}$

The above points concern only narrative evidence of the intimate relationship between some philosophers and narrative; the evidence suggests that the wider the glance we cast across the philosophical field, the clearer it becomes that an exclusive preference for arguments over narratives is somewhat provincial. Just as important as this historical point is the rhetorical alliance between narratives and inferential arguments, even as there are notable and undeniable differences between these forms. Without subsuming one class into the other, we could say that narratives often function interpersonally as arguments, and that arguments usually have narrative elements. Walter Fisher made the former point when he noted that two famous narrative works, Death of a Salesman and The Great Gatsby, provide a kind of 
argument against "the materialist myth of the American Dream." ${ }^{25}$ Of course these great books are not good arguments in the sense demanded by many philosophers - the plots do not satisfy formalizable laws of inference-but they do provide a reminder that narratives frequently function as rhetorically effective arguments on topical issues in philosophy. I take it for granted that something like the relative value of material possessions is one of the philosophical topics par excellence, one that is central still in our rationale for the existence of a philosophy curriculum in the first place.

To improve the case for narrative as an element of argument, we should perhaps look to the use of historical narratives within even the most formal philosophical argumentation. Without making any especially historicist assumptions, we can recognize that some degree of narrative is requisite in order to integrate a given argument into a larger context. Philosophers will typically use an abbreviated narrative of disciplinary history to justify a particular essay or other research project: "recent philosophers have assumed or proposed $\mathrm{x}$; I argue $-\mathrm{x}$ " is an historical, narrative justification for the relevance or significance of another argument (I grant arguendo what is only very rarely the case, viz., that the direct arguments for $-\mathrm{x}$ are non-narrative). In addition to these ubiquitous narrative acts of recounting what our interlocutors have said, many of our best arguments against bad theories are very broad, historical narratives. For instance, the best method to counter certain varieties of creationism is to tell an abbreviated history of modern biology. To take a wonderful example from the history of logic: when Collingwood tried to revive the ontological argument, Ryle opposed him by recounting the history of propositional logic. ${ }^{26}$ This was neither a bad, nor an unusual, nor an unphilosophical maneuver. To give a more contemporary example: two sentences prior to this one I abbreviated a story about Gilbert Ryle as part of an argument about the relationship between arguments and stories.

These reminders of the diversity of philosophical expression should discourage any worry that telling stories is unphilosophical. It remains to show both why and how specifically student narratives can serve as the basis of a rigorous and profound philosophical method. The first point to consider is that narrative pedagogy does not dispense with, but rather promotes, argumentative virtues. Learning to argue validly as well as effectively is a primary and indispensable objective of introductory philosophy courses, and the narrative pedagogue endorses these abilities no less than does anyone else. Narratives do not replace, but rather contextualize inferences. In a narrative classroom inferential skills and analysis develop in conjunction with a more commonly neglected pair of objectives, and it is the integration of the various significant learning objectives that comprises one of the 
principal advantages of narrative over argumentative instruction. Two learning areas that are especially important in this context are empathy and self-knowledge, which suffer neglect by most non-narrative methods of philosophy instruction. By setting a human context for all argumentative or inferential activities, narrative pedagogy structures the development of those learning areas.

Although the kinds of narrative that have appeared in philosophical literature are diverse, narrative pedagogies aimed at self-knowledge concern a more limited selection of narrative forms. The reflective assignments in a narrative introduction require that the student recount experienced or observed events, although in some cases it will be appropriate to borrow also from cultural media (novels, film, history, etc.). The virtue of first-person narratives is that their contents are familiar to the student, and so provide a meaningful context for all subsequent philosophical analysis. Argument in this case does not occur in an academic bubble, but rather the initial and primary acts by the student already belong to incipient self-knowledge. This explicit application and lived development of argument simply does not take place in courses that deal primarily or exclusively with arguments from books (and their often unrealistic illustrations). Unlike argumentative assignments, narrative assignments can foster and assess self-knowledge in a direct and explicit manner. In that case narratives begin to provide a life context in which inference and analysis increase a student's life- and self-understanding. A student in an exclusively argumentative course will perhaps likewise obtain some form of self-knowledge by applying learned arguments to events in or aspects of her own life. But the argumentative pedagogue does little more than hope that such application occurs, whereas the narrative pedagogue has targeted such an outcome in every assignment and exercise.

In order for these goals to be met, it is imperative that students and instructors actively engage in storytelling. It should be clear then that narrative pedagogy is distinct from more traditional pedagogies that merely employ narrative cultural products as media. The many advantages of narrative pedagogy as a method derive from the fact that the learner's activity is the focus, and what students and instructors do in a narrative classroom differs significantly from what they do in a conventional classroom. Teaching philosophy by watching movies or reading novels, on the other hand, much more closely resembles lecturing on canonical materials than it does narrative pedagogy. A student who watches a film or reads a published story participates in the same manner as a student who reads Plato or attends a lecture. The use of popular films or stories might well promote learning, but it is nonetheless a conventional technique with all the same strengths and weaknesses as lecturing, employing textbooks, etc. By contrast, 
a student in a narrative classroom tells her own story, or those of her acquaintances, and investigates the reasons underlying her decisions and her actions. She will also make sense of her everyday observations, and generally use philosophy to correct and improve her own thinking. An unsympathetic objector might worry that such stories will not resemble the more calculated and time-tested narratives I referred to above, just as they do not resemble the more elaborately constructed narratives in popular literature or film. My reply is simply that the goal in introducing students to philosophy is not always to celebrate great artistic productions. If the students learn more from the investigation of the quotidian, then instructors should sacrifice their sophisticated sensibilities. It is even likely that students can better appreciate great works of philosophy, literature, or film, after they have developed a degree of self-knowledge and empathy.

There exists in corners of our discipline a further skeptical view about narrative, one that could perhaps lean on recent writings by Galen Strawson. ${ }^{27}$ The worry is that first-person assignments such as I propose are as much obstacles to self-knowledge as they are paths to it. Student narratives, the skeptic argues, typically reflect socially scripted stories. In speaking or writing of their "selves" the students thus engage in a very unreflective sort of behavior. Having recognized this problem, theorists of narrative pedagogy developed criteria for assessing selfknowledge that appeal to the individualization of culturally prominent narratives. They argue, and my experience confirms, that narratives become progressively individualized as narrative learning proceeds. ${ }^{28}$ My own method of meeting this objection concedes even more ground to the skeptic: one road to self-knowledge lies in identifying, and becoming disillusioned with, precisely that series of culturally prominent and unreflective narratives to which the students will initially appeal. ${ }^{29}$ Students in a narrative classroom will not simply recount narratives unreflectively. Rather, since it is philosophy we are discussing, the conceptual and ideological underpinnings of the initial narratives will be subject to intense scrutiny. All the resources of standard academic philosophy can serve towards the completion of this important task.

Just as narrative assignments target self-knowledge in a uniquely effective way, so do they develop empathic understanding. In a classroom setting, the student of narrative philosophy will also listen to the stories of others, thus providing opportunities for an explicit focus on empathy that is not otherwise available. ${ }^{30}$ Students will reason about each other's stories in a manner that requires considered regard for the specific agents under discussion. Since argumentation in this context is not defensive and justificatory, the usual barriers between students disappear in the narrative classroom. In addition to these listening exercises, a well-designed first- or third-person narrative assignment 
develops empathic understanding independently of student-to-student interaction. The reason for this is that in relating narratives the students assign reasons to the persons in their lives, with an aim to assessing and evaluating those reasons. Assignments can be constructed that require the students to inhabit the position of their adversaries in lived disputes or disagreements. The assignments thereby reflect empathic understanding in a direct and explicit manner that permits easy incorporation into both grading and assessment. On the other hand, a student who learns to analyze arguments about content not taken from her own life or that of her peers, will perhaps learn empathy as an eventual and very indirect result of the assignment. But even in this best case such learning is not a direct or planned outcome of the pedagogy. ${ }^{31}$

In prioritizing the learning objectives of self-knowledge and empathy the narrative philosopher, just like the argumentative philosopher, appeals to a Socratic theme for some narrative identity: Socrates' most famous dictum is "the unexamined life is not worth living." 32 Narrative philosophers and our students profess to be the heirs of this introspective Socrates rather than the anti-rhetorical version of that sage. The task of the narrative pedagogue is not to demonstrate any lofty argumentative conclusions, but rather to develop a methodized communication of the reflective life. The need for such reflective living and self-examination is only increased by the myriad opportunities for self-expression that our culture offers. Introduction to Philosophy is one powerful medium that can help today's young people transition from narcissistic or thoughtless self-expression to reflective, self-critical, and Socratic living. Lessons of how to reflect on life, as conceded above, will perhaps be occasional, accidental side-effects of good non-narrative philosophy instruction. The narrative philosopher, however, allows such reflection to form the much of the substance of the curriculum, and in doing so prioritizes the significant learning experiences that foster self-knowledge and empathy. Teaching self-knowledge in particular requires that the course provide opportunities for detailed and methodical investigation of the living concerns of those students, and narrative assignments seem to be the only efficient and direct method of incorporating such concerns into the curriculum.

\section{II}

In this section I wish to elaborate the relationship between narrative pedagogy and some standard philosophy curricula, as well as offer some brief examples of narrative assignments. In doing so I hope to explain how these assignments can either complement existing syllabi or replace canonical, textual approaches altogether. In both cases narrative exercises serve to increase the relevance and flexibility of the 
curriculum, thereby forging a more intimate relationship between course content and learning outcome. A narrative procedure, one that begins with a familiar story and moves upwards to arguments or theories, places some clear limitations on curricular choices. My expectation is that few instructors will find a place for narrative in a unit about, for instance, the reality of numbers. The students in that case would not have previous experiences or observations that illuminate the subject matter, and conversely the subject matter will not illuminate much about the students' lives, experiences, relationships, etc. A relationship between content and learning outcome is possible in the case of very many, but perhaps not all, topics that are commonly covered in introductory courses.

Since the two principal merits of curricula that include narrative are flexibility and relevance, I proceed by giving for each of these first a rationale and then a brief discussion of its implications for content selection. The insistence on curricular flexibility rests on a relatively uncontroversial premise: introduction to philosophy is not the introduction to any particular topics or content. A course in introduction to philosophy is partly an institutional context for the development of a cadre of basic cognitive or intellectual skills such as self-knowledge, empathy, interpretation, and argument; such a course is also, perhaps, a way of integrating students into wide traditions of reason-giving, reflective living, and other such things that are similarly content-flexible. Narrative pedagogy's more consistent emphasis on curricular flexibility better fulfills the demands of learning-based teaching by allowing student need rather than an instructor's educational idiosyncrasies to inform decisions about content. This only generalizes on a point that many good teachers already concede, viz., that our core curriculum should be variable in content. Whereas the usual implication of that admission is only that topical content can vary from course to course or teacher to teacher, the narrative pedagogue extends the point by allowing the content to vary somewhat from hour to hour, student to student. In the former case the concern is with professorial academic freedom; in the latter case the concern is with a more important issue, viz., significant student learning.

Narrative assignments will increase the flexibility of a given curriculum whether they complement an existing syllabus, or replace canonical sources altogether. In the former case, instructors will need to emphasize those topics for which an assignment directed at application or self-knowledge is appropriate. That narrative assignments can supplement at least some classically philosophical topics is easy enough to see, and in these cases narrative makes philosophy into a fluent extension of life: a student who studies the theory of responsibility will recount a dispute with a roommate over the attribution of 
blame; a student of Aristotle's Ethics will discuss her decision whether to abandon an abusive or disloyal friend; ${ }^{33}$ a student of forgiveness will tell of his struggle to forgive his alcoholic father; a student distressed over parental pressures will resolve this worry with a study of parental authority or the etiology of decision-making. Of course not all life events are so tragic: students who observe superstitions or phobias among their friends or family are in need of a study of aberrant belief; students who become jealous lovers have ample ideas to develop from this context; and of course those bothered by political or social problems will have an especially easy time merging life concerns, self-understanding, and the activity of a philosophical classroom. In these cases the narrative assignments can highlight for students the applicability of standard materials, as well as make their life outside the classroom into a laboratory of philosophical study.

In cases like mine in which narrative replaces standard curricula entirely, the programmatic learning objectives become tools for the organization of the class syllabus. Since there is less emphasis on content categories such as figures, topics, and core areas, the structure of both class activities and written assignments reflects the desired learning outcomes more faithfully. For example, I begin my courses with a sequence of written and oral assignments designed to reveal the default identity/beliefs of the given student demographic. The assignments and activities of the next two weeks divide purely according to assessment criteria: Can the student criticize the narratives or ideologies into which she was indoctrinated? Can the student attribute good and consistent reasons to the authorities he criticizes? Can the student assess the reasons he attributes to the persons in question? Can the student consider multiple or competing sets of reasons before attributing any to the persons in question? Can the student engage in additional forms of reasoning (e.g., counterfactual thinking, empathic understanding) in this context? A unit of two or three weeks needs only a few distinctions and tiers of learning objectives for its organization, with student or instructor narratives supplying the content. The flexibility of topical content contributes to this heavily outcome-based pedagogy by removing the illusion that mastery of any definite, immigrant content (e.g., Aquinas's third way or Hume's paradox of induction) is the goal of a particular course unit.

The abovementioned series of learning objectives guides the content of the assignments. For instance, the first objective in the list requires the student to adopt a critical disposition towards her authorities and her education. I arrive at this objective simply by asking what I can reasonably expect of students who are in their first week of academic study in philosophy. It would seem unfair to expect of them the sophisticated reading or reasoning skills required to attack a classical 


\section{KEVIN J. HARRELSON}

text or argument: this is what they should exhibit perhaps at the end of the semester. Instead I conclude that they should merely share an open-minded disposition and a willingness to become critical about their default beliefs or educational and cultural biases. With this kind of requirement in mind, I arrive at the following very simple sequence of in-class assignments, intended for beginners who are in their very first week of philosophy class.

Opening day in-class activity:

1. Make a list of things we/you learned as children that we later found were false, or that we later came to reject. (N.B.: instructor or student illustrative storytelling should accompany each item on the list)

This list will inevitably include some trivial items, such as Santa Claus, but will also lead into loftier philosophical terrain, such as sexual prohibitions, myths about American history, and religious topics. The students will thus have all the material on the table needed for an initial reassessment of their beliefs and identity. The second learning objective in the above list introduces the notion of assigning reasons to persons, and requires that a student distinguish reasons from causes and good reasons from bad ones. We thus ask:

2. Why were we told these things?

3. Were the reasons good ones? How would we tell a good reason from a bad one?

4. Does/should this lead us to think differently about those authorities, or relate differently to them?

These questions can be repeated through the ensuing discussion to include higher-level argumentative objectives:

- Can the student consider multiple or competing sets of reasons before attributing any to the persons in question? (This ability will be fostered and tested by means of the peer disagreement that arises in any lively discussion)

- Can the student engage in additional forms of reasoning (e.g., counterfactual thinking, empathic understanding) in this context?

Finally a short, written homework assignment encourages the students to perform a more wholesale investigation of their relationship to authorities and to their education, simultaneously building self-knowledge and practicing elementary reasoning skills.

First day homework assignment: 
5. List and describe specific aspects of yourself (beliefs or identities) that have been influenced by specific authorities. How and why did these authorities influence you in just these ways?

E.g., I might be Catholic, socially conservative, and politically liberal. Why am I these things? I can answer this in all the various senses of "why," giving both causes and reasons. Some of the answers might include: I'm Catholic "because" my parents believed, but the influence was achieved by sending me to certain schools.

6. Should I rethink these things in light of what I now know about my previous authorities?

I pursue the initial questions through open, whole-class discussion with an active and engaged population of forty students per section. Specific in-class organizational strategies such as group work, however, can be added without any variation to the course design or content. In the odd case that participation goes slowly (N.B.: an in-class assignment like the one described above will inspire almost universally eager participation), it is important for the instructor to model narrative learning. Narrative instructors must be willing to share life stories and have humanizing learning experiences in the classroom, which encourages students to do the same. Narrative instruction thus requires a personal investment much like the one expected of students, and I do not propose in this article to make anyone's job easier. What narrative teaching can do for your introductory course is increase student engagement, integrate learning objectives, and foster self-knowledge, all while maintaining a high level of argumentative rigor and precision. In exchange for such benefits, instructors will need to risk entering the classroom with only a very loose plan for the proceedings (e.g., one of the argumentative skills mentioned above in addition to an empathic or introspective practice), and they must be willing to learn about themselves and their students in the process of sincere learning exchanges. The narrative emphasis removes from the instructor the security blanket of a mastered text, argument, or other piece of content; our efforts focus instead on the specific intellectual location of the students in the room. ${ }^{34}$

The above suggests why, and to some extent how, curricular flexibility should be embraced in introductory courses. The demands of topical relevance, on the other hand, pertain more directly to specific content-related curricular choices. Relevance requires that we vary the content mainly by studying the relationship between topics under discussion and the students in the room. The underlying premise here is perhaps more contestable than the one that supports flexibility, and so it will require more illustrative evidence: while philosophy indeed 
includes a number of longstanding, so-called perennial questions and topics, these nonetheless possess a degree of cultural embeddedness and even relativity. At the very least, the manners in which philosophical problems or ideas are commonly framed reflect definite social roles or contexts that are too often ignored. Narrative pedagogy thus involves a kind of informal curricular criticism, a matter that is more controversial in philosophy than it is among our humanistic siblings in history or literature..$^{35}$ I wish here to indicate only one aspect of curricular criticism that results from a consistent valuation of topical relevance such as narrative pedagogy requires.

The attempt to introduce narrative assignments tends to magnify the remote cultural contexts of some standard philosophical problems or topics and thus provides perspective on our disciplinary content. A few examples will suffice here: whereas theories of punishment are common in most traditions in political philosophy, I find that my students (mostly middle-class Midwesterners) are typically unconcerned with justifying the existence of penal institutions. This example provides a terrific case-study of the conservative cultural role philosophy has frequently played, and even a very small bit of historical research will reveal that many of the chief political theorists of modernity served as advisors to kings, aristocrats, or other political leaders. The correlate concept to punishment, viz., forgiveness, has not required any such justification and so has not been as central to classical philosophical theories. But since students are in a position to forgive much more than they are to punish, this concept is a much more pressing candidate for their philosophical reflection. This is not to suggest that today's student need not reflect on the rationale behind penal institutions, but rather that philosophy instructors ought to consider in what relationship the students stand to those institutions. The instructor must study the relationship between the students and the content. My students reason about forgiveness as forgivers, but they think differently about punishment. Their experiences of penal authorities will often differ from those of many professors, and these cultural contexts frame any arguments that arise. In any case, a dramatic cultural divide will typically exist between, say, Thomas Hobbes and the student in the back of your classroom. Soliciting narratives from the student enables the instructor to respond to this divide (I assume we already have given Hobbes his due attention).

A more appropriate example of a standard topic that applies extremely poorly to student self-knowledge is the typical section on mind/body and personal identity. That portion of the curriculum that should be most explicitly about the students in the classroom turns out to have nothing at all to do with them. Most current readers include articles (in addition to the oddly requisite and unreadable excerpts 
from Locke) on such matters as brain switching, which articles beg the reader to consider such questions as: if Mike and Tim switched brains, would Mike be Tim and Tim Mike, or would Mike still be Mike and Tim Tim? ${ }^{36}$ I recognize that there is a welter of somewhat interesting questions to pursue in regard to this puzzle, and in the right community I would gladly indulge the conversation. It is even likely that a sufficiently expert instructor could communicate to some students the relevance of that conversation to worries that are applicable for the student. However, even in the best cases the fantastical discussion of brain switching is an extremely inefficient and unnecessary method of arriving at the relevant learning outcomes. Instructors should instead consider that our students have existing ideas about identity, and these can form the starting-point of a much more effective inquiry into this topical area. A series of simple narrative assignments would reveal to the instructor whatever set of presuppositions about personhood are specific to the student demographic. Such an instructor will find that our students have ideas about identity and personhood that practically scream for our attention; by contrast, the philosophy instructor who responds to this situation with a puzzle about brain switching misses the opportunity to be an effective teacher.

For a narrative assignment on identity, I provide my students with a sequence of in-class exercises and out-of-class reflective and observational writing assignments:

In-class prompts:

1. Distinguish the prevalent identity types in your social environment, e.g., athlete, sorority member, hipster, etc. (N.B.: The particular categories may be unfamiliar to the professor, but, as I have just argued, this is a matter of no importance. Instructors must learn inside the classroom how the results of their technical education will and will not apply to the students who pay to be taught by them.)

2. Make a further list of the various types and/or categories in our culture. These categories might divide by, for example, socioeconomic status, social organization, athletic club, religion, or ethnicity (again, instructors must be willing to model illustrative storytelling or probe for student experiences, as necessary).

This initial in-class exercise, which students will of course find intensely amusing, will endow the class with the appropriate set of relevant identity categories. The conceptual discussion should follow naturally from this, including theoretical questions of the sort: 
3. Divide all the categories you have compiled by degree of voluntariness. For instance, I had little or no choice in becoming white, male, and Catholic, but fairly much choice in becoming a professional of one or another sort.

4. Next, make a list of the demands that membership in these categories confers on the individuals who belong to them. I.e., what am I required to be or to do by virtue of my being, for instance, a white male nerd? We will call this the normative content or ethical weight of the category. ${ }^{37}$

It may appear that I have switched the topic a bit here, deviating from an abstract question about personhood to more concrete ones about social categories. While this is partly true, the philosophical terrain that we wish to visit once we have begun from narrative relevance allows of considerable variance. In this case, instructors need only take advantage of the inevitable distinction - expressed of course by students rather than introduced by the instructor-between the "real self" and public categories. Any conversation you wish to have about personhood will then fit squarely within the discussion of student stories and their accompanying preconceptions (though I of course recommend avoiding scholarly puzzles about brain-switching). For my part, I usually continue the above sequence of questions in a direction that deals with identity as a social problem, but any of the classical arguments about personal identity can be approached through this type of ascent from common story to philosophical theory. ${ }^{38}$

An important species of written assignment that regulates topical relevance, one that fits well with the type of in-class exercises I have just described, is the observational assignment. In this type of assignment, students are required to observe, record, and recount examples of some phenomenon that they discussed in class. The benefits of this assignment are twofold. First, recognizing the philosophically relevant aspects of everyday events (like a game, party, or family gathering) requires and ensures a different level of comprehension than in-class testing or isolated writing assignments. Second, student observations will provide material for subsequent in-class discussion, and ensure that such discussions remain relevant to their experiences outside the classroom. The first assignment I give of this type is the easiest, and is unrelated to the identity exercise. I require students to record and analyze superstitious remarks made by their friends and family. We then arrive at some issues in epistemology by reasoning from these examples. In the case of identity, a similar observational assignment follows the in-class exercises, but appeals to categories or concepts that arise in class. We simply take the answers to the in-class questions in 
the ethics of identity, and propose things to observe over the weekend. As the semester progresses, students have more input into the content of such assignments, since they recognize how written assignments are given in response to what they tell inside the classroom. Once these weekend observational assignments become regular, philosophy class begins to infiltrate every aspect of the students' lives.

In an article about narrative teaching I cannot indulge a full criticism of the curriculum as this appears in all the introductory readers, nor can I elaborate an entire semester's worth of narrative assignments. What I can insist upon is that the virtues of flexibility and topical relevance should be primary criteria for selection of course content, whether the course is to follow a textual, argumentative, narrative, or hybrid format. Introductory curricula need not be, and should not be, modeled on some entrenched impression about how research in the discipline best divides. Many an interesting topic or problem simply lack the relevance needed for an introductory course, especially if this serves a core curriculum rather than a pre-professional program. What qualifies any problem or topic for an introduction to philosophy is primarily its ability to inspire today's youth to engage in a respectable and responsible degree of philosophical reflection or investigation. And what qualifies a problem or topic for this is either its relevance to the experiences and preconceptions of the student, or its flexibility in applying in diverse contexts to diverse persons. Narrative pedagogy offers just one especially clear, straightforward, and effective method for ensuring that our curricula possess such relevance and flexibility. More importantly, it makes the relevance, significance, and nobility of our discipline palpable to even those students who have otherwise little inclination for philosophy.

\section{III}

In this section I outline a few further principles of narrative assignments, grading, course design, and other matters of practical concern. ${ }^{39}$ Much of the previous two sections concerned only the rationale for narrative teaching, and it remains to discuss who can adopt a narrative pedagogy as well as lend more detail as to how they might do so. To address the question of how narrative can be implemented, I offer below a detailed assignment sequence that covers a unit on a canonically philosophical topic, viz., the theory of responsibility. As far as who can adopt a narrative method, my short answer is "any brave philosophy instructor who teaches introductory courses with a class size of fifty students or less." That narrative instruction is risky is something I mentioned in the previous section, and the emotional investment in my own first semester of completely text-free teaching was significant. The 
benefits, however, are well worth the risk. That narrative pedagogy is also flexible in regards to topical content is a point to which I devoted sustained explanation, and it follows that narrative instruction can be adapted to fit most reasonable departmental content restrictions. As far as the workload of narrative instruction is concerned, there will be significantly more grading of written assignments, but also less class preparation time. Students in a narrative course write more and read less, with the presumption being that a carefully designed semester of writing assignments can help students develop the complex reasoning skills needed to later read philosophical texts effectively. This means that the instructor may enter the classroom only with bravery and a set of learning goals, but will often leave the room with written homework assignments. ${ }^{40}$ My students write at least one 500-word assignment weekly, with longer essays arrived at monthly.

In the following I first detail a narrative sequence in the theory of responsibility, which should both illustrate the method of narrative course planning and remove any worries that narrative is ill-suited to canonical content. As above, the narrative method should here be contrasted with a standard textual and argumentative method. A student who learns the theory of responsibility in a traditional manner will first learn a number of distinctions as well as competing theories. Assuming the student reaches the achievement level expected by the instructor, he will correctly apply the distinctions and assess the arguments for the various theories. Perhaps there will be a choice of a favorite theory and the defense of a particular belief chosen from among several options. The principal action performed is defensive and justificatory (something the moral and political value of which requires a separate justification that is almost never given). The detached, hypothetical example of which some philosophers are so fond serves as a substitute for real application. How to find examples of this in her life is a matter left to the student, since the instructor neither assigns nor assesses this more important form of application. Self-knowledge and empathy are at best occasional and indirect outcomes, as there is nothing in this particular kind of activity that addresses these goals. Indeed, there is nothing preventing a philosopher trained in this manner from eventually publishing essays on philosophical topics, even in top journals, without ever achieving much in the way of application, empathy, or self-knowledge.

A student who learns the same topic in a primarily narrative manner will fare much better. Recalling one or more recent or significant dispute over the attribution of responsibility (I have not met a student who could not quickly produce several of great importance to him/ her), the student will attribute and assess reasons to all parties to the dispute. A scaffolded sequence of written narrative assignments, 
combined with oral classroom exercises, will yield some disciplinary content: first give a reason for one side, then for the other, then draw a general implication for each, then posit hypothetical differences that alter the reasoning, then test the general implications against other examples you are familiar with, etc. In this manner the student who deals with the positions implied by a previously experienced circumstance learns distinctions and devises competing theories similar to the ones learned by the argumentative student. This analytical result, however, accompanies a wide selection of additional aims. The principal actions performed by the student are both empathic and decisive; the student understands her peers, family, and other interlocutors better, and also resolves a life issue. The sequence of assignments I follow here is rather more involved than the two assignments I described in the previous section, although I omit a number of conceptual niceties that instructors can supply according to their own preferences (N.B.: it is important to remember in all cases that these are only models specific to the context of my classroom, not proposals for universal adoption).

In-class exercise \#1:

1. Make a list of the ways in which you/we influence the actions of other people (N.B.: the storytelling that accompanies this exercise will be particularly vibrant). ${ }^{41}$

2. Add to the list some ways in which others influence your/ our actions.

Introspective addition:

2a. Write a list of the most common strategies that others use on you, in order to determine which "forms of human susceptibility" you possess. Make a corresponding list of the ways in which you manipulate the actions of others.

In-class exercise \#2:

3. Add to the initial list some ways in which you/we influence the choices and desires of other people. Did the initial entries already include this level of manipulation/ influence? Distinguish the cases in which we merely influence someone's action (make them do what we want) from those in which we influence their desire (make them want what we want [them to want]).

4. Does the notion of choice preclude influence? What else belongs to choice if it is not the absence of influence? 
5. Add to the list some ways in which social institutions (advertising, school, etc.) influence our actions, desires, and/or choices.

Written narrative assignment:

1. Consider an example (or series of examples) involving difficulties with assigning or attributing responsibility. The example(s) can be from personal experience, hearsay, or media. (N.B.: the examples should be such that the facts of the case-who did what-are uncontroversial; the questions should pertain only to the moral criteria for attributing responsibility). Describe both (or more) sides of the dispute sympathetically, without deciding which side you think is right. You should have a short list of considerations for each side.

The in-class exercises are designed to inspire reflection and discussion on the causal and social contexts of decision-making. This will give the students an initial vocabulary and set of distinctions, drawn from their own experiences, with which to assess controversies over responsibility or blame. The narrative assignments provide us with a wealth of examples (at least one per student, so forty per course section) to analyze, and this analysis occupies the next several class sessions. We need to move from the student narratives towards a theory of responsibility.

In-class responsibility debates:

Choose a student, take a volunteer, or structure some other sort of exchange of responsibility narratives. Allow the students to disagree in their judgments (they will), and ask them to distinguish criteria by which they judge. Such items as the following will typically arise, although it is important, as always, to allow the students to author their own list: the causal history of the relevant action; the knowledge and understanding that the agent had of the situation; the consequences of the action (foreseen or unforeseen; immediate or remote; etc.); alternative possibilities that were available to the agent; control the agent had; antecedent choices the agent made.

We slowly arrive at the following essay assignment, which assumes a form similar to that of a standard academic essay on responsibility. The narrative assignment, if appropriately completed, will have provided students with their own initial examples. They then arrive at a thesis in the following steps, which are modeled in-class collectively (or in groups) before being executed individually in written form:

Written essay assignment: 
1. Recount your relevant responsibility controversy.

2. Discuss the example(s) in relation to the list of criteria we constructed in class.

3. Hypothetically change the details of the examples as concerns the criteria listed discussed in 2. Address how such changes affect how/whether responsibility should be attributed.

4. Construct a general definition of responsibility including reference to at least some of the criteria listed in 2 . (N.B.: making the abstraction from hypothetical variant on a lived story to a definition or thesis is an extremely difficult task, and requires several in-class sessions for practice, as well as a gradual skill-building plan throughout the semester)

5. Imagine attempted counterexamples that will challenge your definition. Explain the counterexamples, and address them in your defense.

How does the narrative student's learning outcome differ from the student who learned this topic only textually or argumentatively? The formal reasoning processes of the two students are the same or similar, but in the case of the narrative student there is self-knowledge; there is also empathy, to the extent that the student has reasoned also for each of the persons involved in an event significant to her life; and there is a degree of application that is not assigned or assessed by a student in an argument-based course. That a student who learns by applied narrative also reasons much better than a comparably talented student who learns only extant arguments and theories is something for which I can give only anecdotal assurance. But even if this expected advantage never receives empirical confirmation, the assigning and assessing of additional activities and outcomes already favors the narrative method over its argumentative cousin. This is not to mention that whereas the argumentative student has only defended an often previously held belief, the narrative student has empathized, acted, and become a more reflective, autonomous human being.

The dichotomy I outline here between argumentative and narrative methods is of course overstated. As I argued in the opening section, narrative and argument are complements, not contraries. As such it is easy to integrate these approaches to one another. For instance, the instructor who introduces a selection of theories or arguments at the beginning of a unit can append a narrative assignment as an application of the theory. The narrative assignment can apply in regard to a particular distinction, theoretical claim, or other piece of argumenta- 
tive or textual content. Continuing the above example of a unit on the attribution of responsibility, the instructor can add narrative to the existing syllabus in the following ways, among others: "recall or find an example from your life, or from prominent cultural media, in which the distinction between willing and consequence framed an argument over who is responsible for a misdeed or wrongdoing"; or, "take a recent controversy over responsibility in your life, and analyze it according to the distinction between degree and scope of blameworthiness" (in these cases the instructor will need to take measures to ensure that the correspondence between narrative and theory is not artificial). Once this initial directive for the narrative has been given, the instructor will add various argumentative criteria to the assignment. The argumentative steps should be distinguished for the student in a careful and gradual matter, since the relation of application to theory is arguably more difficult than is any theory in isolation from application. If the steps are given in sufficient detail, then the instructor in this way can methodically ensure and check the application without sacrificing argumentative rigor.

A similar hybrid approach is possible for instructors who wish to begin with narrative and move towards textual, canonical arguments. This method is in one sense preferable to the last, since it will be easier for the instructor to select theories to match the narratives than it will be for students to select narratives to match pre-selected theories. In another sense, however, it is more difficult, since it requires more deviation from a standard textbook syllabus. In any case, the instructor begins in the narrative mode: "Relate one or more recent or significant dispute over the attribution of responsibility; assign reasons to the relevant parties to the dispute, etc." After adding the additional argumentative steps (draw general implications, hypothetically manipulate the details so as to fix distinctions, test the general claims against other examples, etc.), the instructor can introduce the students to carefully selected disciplinary materials. Even the most inexperienced students will have some success reading professional philosophy once these steps have been practiced in application to their own lives, to other observations, or to cultural media. The initial foreignness of philosophical thinking and writing will not appear in this case, since the students will see the professional authors as simply executing more precisely something they have already tried. The assumption behind this fourth method is that it is possible and beneficial to practice philosophy as a preliminary to reading it.

Since narrative assignments can include these various degrees of argumentative detail, they need not pose any special problems for grading. The narrative practice serves only to relate the content to the students' experience and to the learning outcomes for the course. 
The fact that arguments, theories, and ideas are framed around such meaningful events does not require that the instructor assess the assignments much differently than otherwise. To remain with the example of responsibility: my students must decide and resolve the cases that their narratives introduce, justify this decision in terms of a general definition or theoretical claim, and test that definition or theoretical claim against other examples and counterarguments. Whether the theoretical claim is abstracted from the narratives or borrowed from a book will determine the kind of learning that takes place, but it does not always change the instructor's manner of assigning a grade to the result. Perhaps some credit can be given (and it is in my case) for relating the topical content to a relevant context, or for picking a story that illustrates appropriate or interesting problems. But since much of what narrative students do is engage in rigorous and precise discussions of philosophical problems, they will receive grades in accordance with how well they do so (according to the specified criteria). Narrative, to put it simply, offers a starting point and a context for inquiry; much else remains unchanged. ${ }^{42}$

While narrative assignments do not need to pose special problems for grading, they can assist instructors in developing better fair grading procedures. One reason for this is that students move from narrative to argument only in small, definite steps, allowing instructors to make their grading criteria more self-conscious and explicit. Instructors can assign grades to narrative assignments in accordance with successful completion of each step, so the narrative and argumentative moves have, as Daryl Close recently advocated, "determinate weights expressible as fractions of the final grade." ${ }^{43}$ For instance, when I give the final assignment on responsibility, the students receive up to 15 points (out of 100 for the course). The 15 points are further divided according to the various steps taken from initial storytelling to theoretical essay: 3 points for selecting a relevant narrative that meets the specified criteria; 3 points for properly including a selection of basic concepts that we developed in classroom exercises; 3 points for relevant and effective hypothetical modifications of the narrative details; 3 points for a precisely stated definition or position that decides the specific dilemma at hand; 3 points for successful counterexamples to the definition or position, with a reply to the counterexamples. Each of these five steps will be further specified in class and in writing for the students (e.g., one point for the relevant counterexample, one for drawing its implication, etc.), so that the graded assignment becomes a fairly precise calculation based on evidence of conceptual and cognitive skill.

As should be clear from the previous section, the criteria that drives these assignments is determined principally by a definite set of learning objectives rather than any borrowed content, although there should be 
some conceptual or thematic continuity over a given unit. The learning objectives for the assignment on attributing responsibility admit elaboration on several tiers. Argumentatively, the student has practiced such skills as attributing reasons, assessing opposed reasons, drawing general consequences, and applying hypothetical conditions. The grading for the assignment took place mainly on this first tier, though this need not be the case for all assignments. A second tier of objectives focuses on applications that the student has practiced: sympathizing with a disputant, criticizing a social norm, etc. The specific activity of the classroom, assessing a given case of reason-giving, is almost guaranteed to continue outside the classroom. The student has methodically reflected on a matter of importance to her, and this cannot fail to have an impact on the situation in question. Because of this, it is reasonable to include some of the lofty, ancient ideals such as happiness and wisdom as comprising a tier of course objective. The educational research on narrative learning tends to include such aims, though I do not propose that instructors consider these ideas when assigning grades. ${ }^{44} \mathrm{~A}$ few additional assignments like the above-described will yield more ideas, and the sum of these can in turn be organized into a functional sequence.

Although it is possible to give narrative assignments and grade only on the argumentative criteria, some instructors will prefer to arrange assessment based on second-tier objectives. In this case, a small bit of ingenuity is needed. For instance, the first assignment might ask for a responsibility narrative in which the student has a stake in the answer: "Recount a dispute over responsibility in which you take/took a side in the argument." A second assignment can then be given: "tell the story from the vantage point of someone who thinks the other person is right, giving all the necessary arguments and detailing the relevant criteria." In this case, the student is faced with an explicit and fair test of the learning objective "sympathizing with a disputant," and the instructor can easily assess whether this objective has been met. Similar devices can be used in the case of other second-tier objectives.

However one wishes to correlate learning objective with grading, a definite list of objective should be compiled by the instructor, and shared with the students, at the beginning of each semester. I divide my relevant learning objectives in an introductory philosophy class into the following three tiers, in progressive level of abstraction and importance:

Tier One, argumentative skills: distinguishing premises, attributing reasons to persons; drawing generalizations; devising counterexamples; using hypothetical conditions; composing multi-voiced texts/narratives, etc. 
Tier Two, lived applications: revising default beliefs; criticizing social norms; empathizing with a rival; achieving relative consistency among commitments; integrating identity, belief, and action, etc.

Tier Three, higher-order goals: happiness; wisdom; autonomy; selfawareness, etc.

Each assignment should practice one or more of the lower-order skills with a progressive degree of difficulty, and what are here listed as second-tier goals admit of development and assessment that is almost as explicit. Such objectives can also receive differential emphasis over the course of a semester, and the distribution of this should cohere with the course plan. Each of the first tier objectives can be repeated in the context of each of the second tier aims as follows. For example, one might assign some narrative about a social institution such as marriage. In composing narratives in regard to the norm, the students might be required to attribute reasons to various persons or (rationales to certain institutions), state hypothetical conditions, draw generalizations, etc. Sequences of assignments will address different norms, each of which will incorporate various first-tier goals. The semester will include sequences covering different second-tier aims: sometimes the students should be synthetic and critical, sometimes analytical and justificatory, sometimes reflective and confessional, in accordance with how a given instructor devises specific goals for the students. But a definite sequence of assignments organized according to what I call secondtier goals, one that also incorporates into each assignment a selection of appropriate argumentative skills, should always lead to exceptional results in self-knowledge, happiness, autonomy, etc.

To the extent that the students require a more topical sequence or syllabus, this can be rather easily provided. One must recall what I argued in the first two sections about the content of narrative: the topical sequence is determined as much (preferably more) by the student demographic than by the instructor's background or research. The topics should pertain especially to the instinctive and unreflective narratives that the given student demographic prefers. Coherence among topics will be provided by the narrative tendencies of the students: if the students are regaling each other with tales of responsibility attribution in one unit, what follows in the next unit need only allow them to develop ideas they already began. The semester plan requires only that the student develop the requisite skills while constructing some coherent sequence of narratives (of herself, some subset of communities to which she belongs, or institutions in which she participates), including or emphasizing her most significant actions and decisions. My courses follow a sequence that begins with criticism of authorities, and then moves to narratives of responsibility, identity, and more complex 
social concerns (friendship, sexuality, etc). But there is nothing sacred in the details of a given instructional sequence, and the principles of narrative pedagogy require that it remain both flexible to student need and open to revision on the basis of the endless stream of involuntary feedback that student narratives supply. In constructing narratives and making observations, the students provide the details that assure topical unity and inform future curricular choices by me. In my experience students frequently marvel at the end of the semester at how cleanly all their assignments fit together, although I recognize that the fit was provided by their own lives. This last, of course, is the object of study to which an unapologetic Socrates once directed us.

\section{Notes}

1. The literature on this is especially large, but Narrative Means to Therapeutic Ends, by Michael White and David Epston (Norton, 1990) is the recognized classic. A recent approach with both rich evidence and wide cultural context is Innovations in Narrative Therapy, by Jim Duvall and Laura Beres (Norton, 2011)

2. The classic texts in this category are by Walter Fischer, especially "Narration as a Human Communications Paradigm," Communications Monographs 51 (1984): 1-22; and "The Narrative Paradigm: An Elaboration," Communications Monographs 52 (1985): $347-67$.

3. The literature in this category is, again, voluminous. A recent work of note is Narrative Pedagogy: Life History and Learning by Ivor F. Goodson and Scherto R. Gill (Peter Lang, 2010). In the following I refer frequently to this text.

4. See Jerome Bruner, "The Narrative Construction of Reality," Critical Inquiry 18:1 (1991): 1-21.

5. See Jerome Bruner, "What is a Narrative Fact?," Annals of the American Society of Political and Social Sciences 560 (November 1998): 17-27.

6. Ohio State University seems to be the forerunner in this trend, with an interdisciplinary program in narrative studies that also houses a journal called Narrative and a book series on narrative theory. There are a number of such journals among both literary critics and social scientists, such as the older Journal of Narrative Theory and Journal of Narrative and Life History.

7. Sociologists have suggested to me that they are in a worse spot in regard to narrative, since the singularity of stories threatens the quantitative aspect of evidence.

8. Narrative is more easily practiced in a small classroom environment, but standard introductory courses at public universities like mine have not proved too populous. For large section teaching of greater than about fifty students, a number of practical problems could arise. This essay, however, assumes that the class is small enough for the instructor to grade many individual written assignments.

9. Goodson and Gill, Narrative Pedagogy, part 2 (pp. 73-154) offers a good defense.

10. See the articles collected in Melanie C. Green, Jeffrey J. Strange, and Timothy C. Brock, Narrative Impact: Social and Cognitive Foundations (Psychology Press, 2002). Especially helpful on this topic is Melanie C. Green and Timothy C. Brock, "In the Mind's Eye: Transportation-Imagery Model of Narrative Persuasion," 315-41. 
11. This list is partly adapted from Dana Benelli, "History, Narrative, and 'Innocence Unprotected,"' SubStance 15:3 (1986): 20-35.

12. For a recent discussion of narrative in Plato, see the contributions in Philosophy in Dialogue: Plato's Many Devices, ed. Gary Alan Scot (Northwestern University Press, 2007.

13. Ann-Marie Bowery's "Know Thyself: Socrates as Storyteller" (in Scot, Philosophy in Dialogue, 82-109) elaborates this problem by distinguishing direct and reported dialogues in Plato.

14. There is a much richer literature on this topic. For recent references, see Plato's Myths, ed. Catalin Partenie (Cambridge, 2009).

15. Historians of philosophy, for instance, might require that we learn the text in its original language, study all the texts that the author studied, examine the translation history of some key terms, assess the reception and effective histories, and take other measures prior to considering abstracting an inferential argument from a philosophical text.

16. This and the subsequent sentences cumulatively refer to a few dozen classic texts in the history of philosophy. I will spare my reader the many unnecessary references.

17. Daybreak \#481 is a good text, though not the most frequently cited on this issue.

18. I refer to his Journey of the Mind to God, which is still in fairly wide paperback circulation.

19. In previous publications I have been guilty of this one myself.

20. In Geschichten verstrickt. Zum Sein von Ding und Mensch (Felix Meiner, 1953); Klostermann has released a recent (2004) edition of this title.

21. Alasdair MacIntyre, After Virtue (University of Notre Dame Press, 1981). See especially chapter 15 on "The Virtues, the Unity of a Human Life, and the Concept of a Tradition."

22. Sources of the Self (Harvard University Press, 1992) and The Ethics of Authenticity (Harvard University Press, 1992).

23. English versions of the three volumes of Time and Narrative were published by the University of Chicago Press in 1990. The massive tome Memory, History, and Forgetting (University of Chicago Press, 2006) is perhaps a more relevant text. There is a considerable secondary literature on these works. See especially Paul Ricoeur and Narrative, ed. Morny Joy (University of Calgary Press, 1997).

24. Richard Kearney's On Stories (Routledge, 2001) is a good example that nonetheless remains within the scope of Ricoeur's work.

25. Fischer, "Narration as a Human Communications Paradigm," 11-14.

26. Ryle's essay appeared in Mind 44, no. 174 (n.s.) (April 1935): 137-51 (reprinted in The Many-Faced Argument, ed. John Hick and Arthur C. McGill [Macmillan, 1967], 246-274).

27. See Strawson's "Against Narrativity," Ratio 17:4 (n.s.): 428-52, which has been widely reprinted and translated. I find Strawson's view well-argued, but also scandalously bad and even dangerous. His view, in a nutshell, is that because self-reflection can be misleading and tricky we should not engage in it. What we can properly glean from the basic psychology that he cites, however, is that there are indeed serious obstacles to self-knowledge. The latter by no means implies that we should forsake the endeavor in favor of a shallow and unreflective existence.

28. Self-knowledge can be difficult to assess, but theorists of narrative have developed some criteria. Goodson and Gill (Narrative Pedagogy, 74-81) suggest that self- 
understanding increases as narratives deviate from socially scripted stories. The extent to which narrative explicitly integrates identity and action is another important criterion, as is explicitness about identity changes.

29. The instructor will need to identify for the given student population just what these narratives are. For instance, if student narratives appeal excessively to individualist notions, then the course should criticize, evaluate, and assess those notions with all the conceptual and argumentative resources of our discipline. I discuss this point in the subsequent sections about, respectively, content and course design.

30. On the special role narrative plays in community-based virtues, see Goodson and Gill, Narrative Pedagogy, chap. 8.

31. In the best cases argumentative approaches will require students to imagine counterexamples or stage hypothetical disagreement. These argumentative tendencies can occasion empathy, but they do not require it.

32. Apology, 38a 5-6.

33. Nichomachean Ethics (9.3) 1165a-b.

34. See Goodson and Gill, Narrative Pedagogy, 78ff. The narrative instructor should nonetheless have an extremely broad knowledge and experience of both the possible academic materials and any life situations that will arise in discussion. She must be more willing than others to improvise, admit confusions, and make unplanned confessions (Have I been unreflective recently in an important aspect of my life?), all of which are sacrifices of professorial egotism that have additional pedagogical value. Most importantly, the narrative pedagogue must refrain from promoting any of her own theoretical or ideological agendas, and instead immerse her attention into the variable concerns of the students.

35. While there are well-known ideological disputes over philosophy curricula (analytic vs. continental, historical vs. ahistorical, etc.), our discipline has not seen anywhere near the extensive, explicit discussion of curriculum revision and criticism that our siblings have undergone.

36. I refrain from giving a particular example, since the point is not to chide a particular philosophical author. The authors of such articles have done nothing wrong, and in context some of this might even qualify as good philosophy. What is neither good philosophy nor good teaching, however, is passing such texts on to students without proper context and in ignorance of the specific learning needs of those students.

37. The literary background to these last terms derives from Anthony Appiah's recent book The Ethics of Identity (Princeton, 2007).

38. We are now equipped to probe some rather abstract ethical questions and apply them to the students' immediate experiences. Most importantly, the entire conceptual architecture is constructed by the manner in which the students answer the initial questions. The content of our exercises is provided mainly by student narrative, and the role of the instructor is only to fit this content into a relevant series of learning objectives. One way to continue the sequence is as follows:

5. One of the many questions that Appiah raises is: "should the normative content of identity be determined essentially by its bearers?" In other words, who decides what the category requires of its members? Is the authority in question limited to members of the category? Example: I once had a black female student complain that Oprah Winfrey does not promote hip hop music on her television show. My uncomprehending response was that Oprah is not a fan of that particular music. On further reflection it would seem that our disagreement was one about the normative content we imagined Oprah's race to have for her. How might we resolve this disagreement? Find and observe some more examples of this sort. 
6. Again taking from Appiah: "is an identity group something you can simply resign from?" To what extent do we have the option to identify our personhood with precisely these public categories?

39. While theorists of narrative pedagogy have extolled the virtues of narrative learning, they have done little to recommend ideas about narrative course design. It is one thing to produce learning outcomes by recounting and revising narratives-something that some instructors do before realizing it—but it is yet another thing to design a semester-long course that structures these profound learning processes. Until there are detailed manuals (not textbooks!) for narrative courses, much of the theory is only promissory. I have begun to assemble materials that will enable instructors of all backgrounds in philosophy to introduce narrative assignments or courses.

40. I mean this figuratively, as contemporary instructional technologies make it so that exchange of paper is a very unnecessary indulgence.

41. My most recent use of this exercise was on January 31, 2012, where two sections developed and discussed a list of more than thirty items here.

42. There is, of course, much more to say about grading in philosophy, and I generally follow the principles Daryl Close proposed in his outstanding recent essay "Fair Grades" (Teaching Philosophy 32:4 [December 2009]: 361-98).

43. Close, "Fair Grades," 371. The quote is from Principle 1.1.

44. Goodson and Gill, Narrative Pedagogy, chaps. 7 and 8, as well as most of the articles in Green, Strange, and Brock, Narrative Impact.

Kevin J. Harrelson, Department of Philosophy and Religious Studies, Ball State University, Muncie IN 47306; kjharrelson@bsu.edu 